\title{
Dynamic modeling of the isoamyl acetate reactive distillation process
}

\author{
Syed Sadiq Ali ${ }^{1}$, SK Safdar Hossain ${ }^{1}$, Mohammad Asif ${ }^{2, *}$ \\ ${ }^{1}$ King Faisal University, Department of Chemical Engineering, PO Box 380, Al-Ahsa 31982, Saudi Arabia \\ ${ }^{2}$ King Saud University, Department of Chemical Engineering, PO Box 800, Riyadh 11421, Saudi Arabia \\ *Corresponding author: e-mail: masif@ksu.edu.sa
}

\begin{abstract}
The cost-effectiveness of reactive distillation (RD) processes makes them highly attractive for industrial applications. However, their preliminary design and subsequent scale-up and operation are challenging. Specifically, the response of $\mathrm{RD}$ system during fluctuations in process parameters is of paramount importance to ensure the stability of the whole process. As a result of carrying out simulations using Aspen Plus, it is shown that the RD process for isoamyl acetate production was much more economical than conventional reactor distillation configuration under optimized process conditions due to lower utilities consumption, higher conversion and smaller sizes of condenser and reboiler. Rigorous dynamic modeling of RD system was performed to evaluate its sensitivity to disturbances in critical process parameters; the product flow was quite sensitive to disturbances. Even more sensitive was product composition when the disturbance in heat duties of condenser or reboiler led to a temperature decrease. However, positive disturbance in alcohol feed is of particular concern, which clearly made the system unstable.
\end{abstract}

Keywords: reactive distillation, process simulator, isoamyl acetate, dynamic modeling, disturbance.

\section{INTRODUCTION}

Reactors and separation units are often the most important process equipment in any chemical process plant. A major portion of the capital and operating cost of a chemical process plant is related to the reactors and separation columns. An alternative to the conventional sequence of reactor-separation units is the reactive distillation (RD) unit where the reaction and separation simultaneously occur, thereby lowering the costs associated with the use of two separate units for the reaction and distillation ${ }^{1-4}$. RD is particularly attractive for equilibrium-limited chemical reactions because the simultaneous removal of products tends to shift the reaction equilibrium toward yielding more products. Moreover, the heat generated by the exothermic reaction can be efficiently utilized to improve the heat economy of the system ${ }^{\mathbf{1}, 5}$. The $\mathrm{RD}$ processes are also particularly effective in the separation of azeotropes that cannot be separated by conventional distillation ${ }^{3,6-8}$.

The cost-effectiveness and compactness of RD processes make them ideally suited for several industrial applications, such as the production of biodiese $\mathrm{l}^{9-12}$ and petrochemicals ${ }^{3,13}$, as well as processes involving alkylation, hydration, hydrogenation, acetalization, etherification, and esterification ${ }^{8,13-17}$. Estrada et al. ${ }^{3}$ compared the conventional process of reactor and separation units with the RD process for hydrodesulfurization. Their group found that the capital and operating costs can be significantly reduced by the RD process without compromising the quality of the product. RD has also been recommended for the esterification of isoamyl acetate ${ }^{4,18-20}$, which is widely used as an additive to flavor processed food and beverages. In an experimental investigation, the conversion of acetic acid with RD was reported to reach $69.5 \%$ as compared with the $18.2 \%$ achieved by a conventional batch reactor ${ }^{18}$. Patil and Kulkarni ${ }^{19}$ determined the esterification reaction kinetics of acetic acid with isoamyl alcohol in a batch reactor. Their group used the kinetic model for the steady-state simulation of the RD process. Their model predictions showed good agreement with the experimental data ${ }^{4}$.
Both the reaction and separation simultaneously occur in the same unit; thus, the RD process is highly sensitive to the feed and operating conditions, which must be carefully monitored and controlled ${ }^{21-24}$. Moreover, the occurrence of multiple steady states and non-linear process gain can also affect the process efficiency ${ }^{6,25}$. RD is a remunerative alternative to the conventional reactorseparator configuration if the challenge associated with its design and control can be appropriately addressed.

From the foregoing discussion, a rigorous dynamic analysis of the RD process is an important prerequisite for predicting its sensitivity to changes in critical process parameters. Consequently, we chose the esterification of isoamyl acetate as the case study in which the simultaneous removal of the one of the reaction products (i.e., water during the reaction) drives the reaction forward. However, before undertaking a rigorous dynamic analysis, a detailed analysis of the economic viability of the proposed RD configuration as compared with the conventional process was carried out with the help of Aspen Plus V 8.6 under identically optimized process conditions. Once the cost-effectiveness of RD was clearly established, we set out for a detailed investigation of the RD dynamics. In this study, we introduced positive and negative step changes in values of three key process parameters, namely, the feed flow, condenser load, and reboiler heat duty. Their effect on the product purity and flow rate flow was analyzed with Aspen Dynamics V 8.4. The magnitude of the departure of the new steady state from the original as a result of the step change and the time taken by the RD configuration to attain the new steady state were of particular interest.

\section{MODEL}

\section{Assumptions}

The proposed model is based on the following assumptions:

- Each tray is considered an equilibrium stage, that is, liquid and vapor streams leaving the tray are in equilibrium. 
- The liquid phase is homogenous in each stage, and the liquid leaving the tray has the same composition as that in the stage.

- The liquid and vapor in the stage are completely mixed.

- The liquid hold up is identical in all stages.

- The vapor hold up in the stage is negligible compared with the liquid hold up of the stage.

- The reaction occurs in the liquid phase.

- The pressure drop is negligible.

\section{Reaction kinetics}

Acetic acid reacts with isopentanol in the liquid phase over the ion-exchange resin to produce isoamyl acetate. The reaction scheme can be written as:

$\mathrm{CH}_{3}-\mathrm{COOH}+\mathrm{C}_{5} \mathrm{H}_{11}-\mathrm{OH} \Leftrightarrow \mathrm{C}_{5} \mathrm{H}_{11}-\mathrm{COO}-\mathrm{CH}_{3}+\mathrm{H}_{2} \mathrm{O}$

The reaction is reversible and exothermic. Its kinetics is given by ${ }^{4}$ :

$$
r=k_{1} C_{\mathrm{CH}_{3} \mathrm{COOH}} C_{\mathrm{C}_{5} \mathrm{H}_{11} \mathrm{OH}}-k_{2} C_{\mathrm{C}_{5} \mathrm{H}_{11} \mathrm{COOCH}_{3}} \mathrm{C}_{\mathrm{H}_{2} \mathrm{O}}
$$

The backward reaction is very slow compared with the forward reaction, so it can be ignored. The rate constant of the forward reaction is given as:

$k_{1}=k_{0} e^{-E_{a} / R T}$

where $k_{0}=61630 \mathrm{kmol} / \mathrm{m}^{3}-\mathrm{s}$ and $E_{a}=41.88 \mathrm{~kJ} / \mathrm{mol}$

\section{Phase equilibrium}

The non-random two-liquid model called NRTL-2 in Aspen Plus ${ }^{\circledR}$ is used for property estimation. The NRTL equation is as follows ${ }^{\mathbf{2 6}}$ :

$\ln \gamma_{i}=\frac{\Sigma_{j} x_{j} \tau_{j i} G_{j i}}{\Sigma_{k} x_{k} G_{k i}}+\Sigma_{j} \frac{x_{j} G_{i j}}{\sum_{k} x_{k} G_{k j}}\left(\tau_{i j}-\frac{\Sigma_{m} x_{m} \tau_{m j} G_{m j}}{\Sigma_{k} x_{k} G_{k j}}\right)$

$T_{\text {lower }} \leq T \leq T_{\text {upper }}$

The relevant physical properties of the components in the reaction are summarized in Table 1 . This table shows that the boiling points of water and isoamyl acetate are the lowest and highest, respectively. Therefore, water will be recovered in the distillate, whereas isoamyl acetate will be recovered in the bottom stream. As the liquid mixture flows down the column, the water evaporates and its fraction in the liquid phase gradually decreases.

\section{Conventional process}

The first step in our modeling strategy was the development of a rigorous model for the conventional process, in which the esterification of isopentanol with acetic acid was performed in the reactor-separator configuration. The flowsheet of the process is shown in Figure 1. The reactor input consists of isopentanol and acetic acid, which appear as separate streams. The details are presented in Table 2. For the reactor model, we used the Aspen Plus RGibbs model, which computes the equilibrium composition at the reactor temperature and pressure by minimizing the Gibbs free energy of the system using the following equation ${ }^{26}$ :

$\frac{\underline{G}}{R T}=\Sigma_{i} n_{i}\left(\frac{\Delta G_{f, i}^{0}}{R T}\right)+\Sigma_{i} n_{i} \ln y_{i} P$

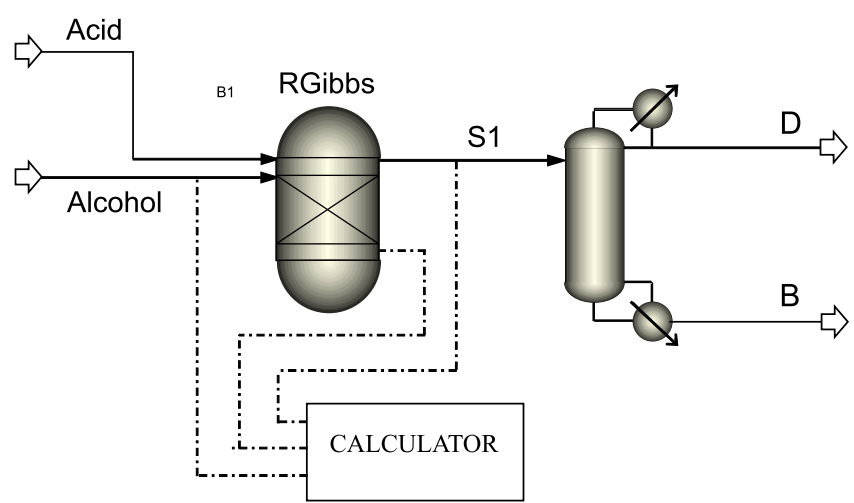

Figure 1. Process flowsheet of the conventional process consisting of sequential reactor and separator units

The extent of reaction at equilibrium is calculated by the abovementioned equation and represents the maximum conversion that can be achieved by a reversible reaction at the specified temperature and pressure. The effluents of the Gibbs reactor were separated by distillation to obtain products of the desired composition. The RadFrac model of Aspen Plus ${ }^{\circledR}$ was used for distillation. This equilibrium/rate-based method performs rigorous material and energy balance calculations at each stage. As previously mentioned, a vapor-liquid equilibrium was assumed at each stage in our calculations. The relevant details of the conventional distillation column are presented in Table 3.

Table 1. Physical properties of components

\begin{tabular}{|c|c|c|c|c|}
\hline & Water & Acetic acid & Iso-pentanol & Iso-amyl acetate \\
\hline Molecular weight & 18 & 60.05 & 88.14 & 130.1 \\
\hline Boiling point $\left[{ }^{\circ} \mathrm{C}\right]$ & 100 & 117.9 & 137.8 & 148 \\
\hline
\end{tabular}

Table 2. Specification of feed conditions

\begin{tabular}{|l|c|c|}
\hline & FEED\#1 & FEED\#2 \\
\hline Temperature $[\mathrm{K}]$ & 363 & 363 \\
\hline Pressure $[\mathrm{atm}]$ & 1 & 1 \\
\hline Molar flow $[\mathrm{kmol} / \mathrm{h}]$ & 32 (Acetic acid) & 35 (Iso-pentanol) \\
\hline
\end{tabular}

Table 3. Specification of the separation unit for conventional and reactive distillation configurations

\begin{tabular}{|l|c|c|}
\hline & Conventional & Reactive distillation \\
\hline Number of stages & 27 & 27 \\
\hline Operating pressure & $1 \mathrm{~atm}$ & $1 \mathrm{~atm}$ \\
\hline Column diameter & $1.5 \mathrm{~m}$ & $1.5 \mathrm{~m}$ \\
\hline Column height & $6.096 \mathrm{~m}$ & $6.096 \mathrm{~m}$ \\
\hline Feed stage & 19 & Above 10 and 16 \\
\hline Reactive zone & - & $10-15$ \\
\hline
\end{tabular}




\section{Reactive distillation process}

The second step was the implementation of the modeling strategy for the RD process. The Radfrac model of Aspen Plus ${ }^{\mathrm{TM}}$ was used. The RD unit (Fig. 2) consists of three sections: the enriching, reaction, and stripping sections. The reaction kinetics was added in the Radfrac model of the reaction section, where the reaction of isopentanol and acetic acid occurred in the liquid phase to produce isoamyl acetate and water. The separation of water simultaneously occurred from the liquid phase to the vapor phase in the reaction section, which lowered the concentration of water in the liquid phase. This phenomenon drove the reaction forward, thereby leading to higher reactant conversion and greater production of isoamyl acetate. The details of the RD column are presented in Table 3. A similar configuration was used by Patil and Bhaskar ${ }^{4}$. The authors performed RD experiments and compared the results obtained by modeling and simulation and found that the experimental results were in excellent agreement with the simulation results. Also, the authors compared their experimental results with Aspen Plus simulation results which also corrobo-

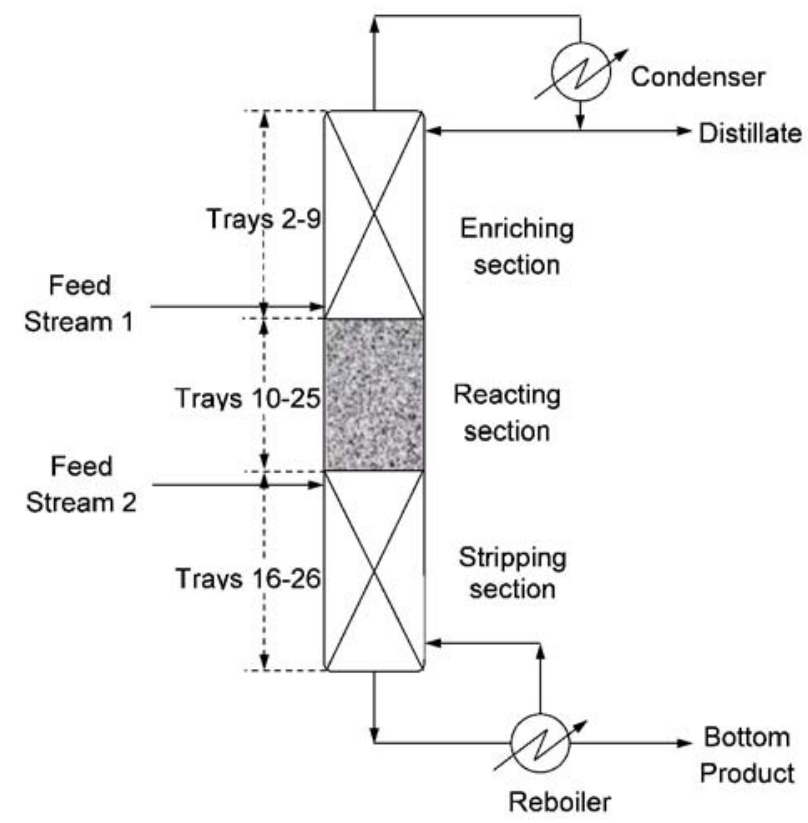

Figure 2. Process scheme of the reactive distillation column

Table 4. Optimized conditions of the separation column rate well within the experimental error. The feed and operating conditions for both cases (i.e., conventional distillation and RD) were kept constant in the present simulation for comparison. The liquid hold up of $0.1 \mathrm{~m}^{3}$ was identical for all the trays.

\section{Optimization of process parameters}

As a part of the optimization strategy, three key parameters were selected to optimize isoamyl acetate production; these parameters were the location of the feed tray, the distillate-to-feed ratio, and the reflux ratio. The optimization results are presented in Table 4 . The reflux ratio was significantly higher for conventional distillation (Case I) compared with RD (Case II). The low value of the reflux, which was mainly water, favored the forward reaction and ensured greater conversion, thereby leading to the higher production of isoamyl acetate in the reaction section. As shown in Table 5, the location of feed streams for both isopentanol and acetic acid were also optimized for Case II. The arrangement in which acetic acid and isopentanol entered Stages 10 and 16, respectively, yielded the best results and was used for simulation in the present work.

\section{RESULTS AND DISCUSSION}

\section{Steady state analysis}

Figure 3 shows the stage-wise variation in the liquid composition of the distillation column for Case I. The condenser was the first stage, whereas the last stage (Stage 27) was the reboiler. The progressive increase in the fraction of $n$-amyl acetate was clearly observed as the liquid flowed down the distillation column. In Table 6 , the heavy key was isoamyl acetate, whereas the light key was isopentanol. The mole percentages of the light key and heavy key in the bottom stream were $0.29 \%$ and $99.71 \%$, respectively. Figure 4 depicts the stage-wise temperature variation in the distillation column, which was operated between $90^{\circ} \mathrm{C}$ and $142^{\circ} \mathrm{C}$.

For the case of RD, the stage-wise variation in the liquid composition is shown in Figure 5. In Table 6, the compositions of the light key (isopentanol) and the heavy key (isoamyl acetate) in the product stream were $0.002 \%$ (possible traces) and $99.85 \%$, respectively. The conversion of isopentanol for both conventional distillation and RD processes is presented in Table 7. Although

\begin{tabular}{|l|c|c|}
\hline & Conventional distillation & Reactive distillation \\
\hline Reflux ratio & 20 & Above 10 and 16 \\
\hline Feed stage & 19 & 0.56 \\
\hline Distillate to feed ratio & 0.57 & 0.9985 \\
\hline Bottoms composition & 0.9971 & 28.66 \\
\hline $\begin{array}{l}\text { Molar flow rate of iso -amyl acetate in } \\
\text { bottoms [kmol } / \mathrm{h} \text { ] }\end{array}$ & 28.73 & 2 \\
\hline
\end{tabular}

Table 5. Effect of the location of the feed stage on the product purity and flow rate

\begin{tabular}{|c|c|c|c|}
\hline \multicolumn{2}{|c|}{ Feed Stage } & \multirow{2}{*}{ Distillate composition } & \multirow{2}{*}{$\begin{array}{l}\text { Molar flow rate of iso-amyl acetate in distillate } \\
\qquad[\mathrm{kmol} / \mathrm{h}]\end{array}$} \\
\hline Iso-pentanol & Acetic acid & & \\
\hline Above Stage 2 & Above Stage 26 & 0.9723 & 13.03 \\
\hline Above Stage 10 & Above Stage 16 & 0.9985 & 28.66 \\
\hline \multicolumn{2}{|c|}{ Single Stream above 13} & 0.997 & 29.39 \\
\hline Above Stage 16 & Above Stage 10 & 0.8835 & 25.95 \\
\hline Above Stage 26 & Above Stage 2 & 0.371 & 10.94 \\
\hline
\end{tabular}


Table 6. Composition of the bottoms for the conventional and reactive distillation columns

\begin{tabular}{|l|c|c|}
\hline $\begin{array}{l}\text { Molar flow rate } \\
{[\mathrm{kmol} / \mathrm{h}]}\end{array}$ & $\begin{array}{c}\text { Convention } \\
\text { distillation } \\
\text { [Case I] }\end{array}$ & $\begin{array}{c}\text { Reactive distillation } \\
\text { [Case II] }\end{array}$ \\
\hline Water & 0.000 & 0.000 \\
\hline Acetic acid & 0.000 & 0.039 \\
\hline Iso-pentanol & 0.083 & 0.006 \\
\hline Iso-amyl acetate & 28.727 & 28.662 \\
\hline $\begin{array}{l}\text { Mole } \\
\text { Fraction [-/-] }\end{array}$ & & \\
\hline Water & 0.0000 & 0.0000 \\
\hline Acetic acid & 0.0000 & 0.0013 \\
\hline Iso-pentanol & 0.0029 & 0.0002 \\
\hline Iso-amyl acetate & 0.9971 & 0.9985 \\
\hline
\end{tabular}

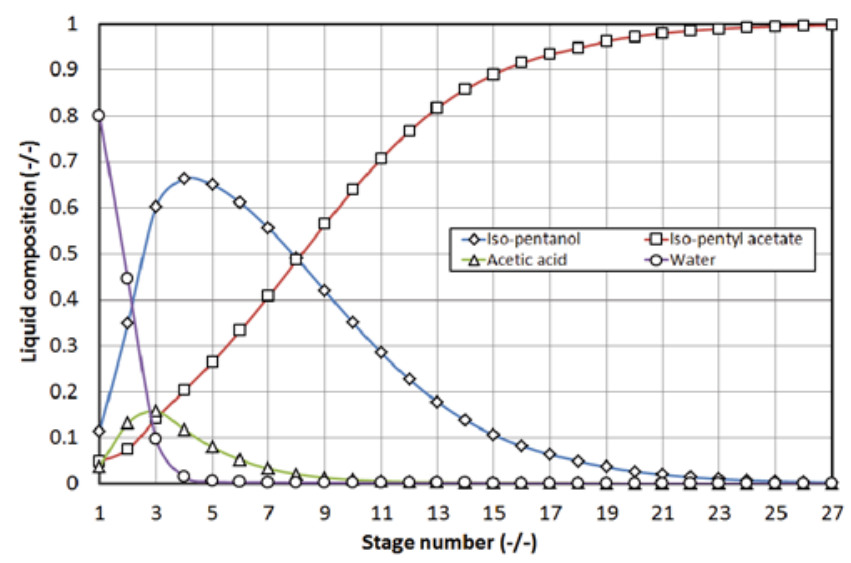

Figure 3. Stage-wise variation of compositions in the distillation column (Case I)

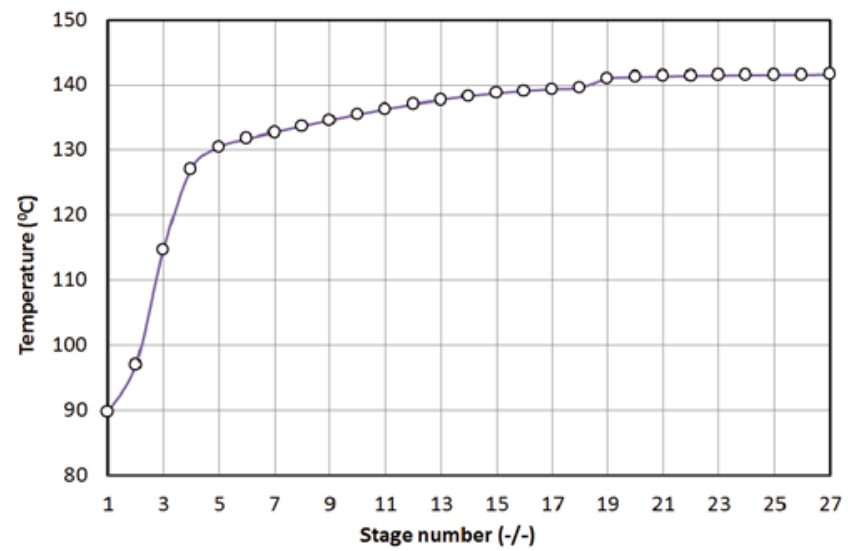

Figure 4. Temperature profile in the distillation column (Case I) at the atmospheric pressure

optimized conditions were used for both processes, the conversion for $\mathrm{RD}$ was $4 \%$ higher. This is due to the fact that the water produced during the reaction in the reaction zone is simultaneously separated from the liquid phase in the RD process. This further drives the reaction forward thereby leading to higher conversion. The liquid phase concentration of isoamyl acetate further increased through the stages because of the separation of lighter components in the stripping section. The conventional Gibbs reactor could not achieve such high conversion with the given equilibrium limitation. The RGibbs model minimized the Gibbs energy to calculate the extent of the reaction at equilibrium, which was the

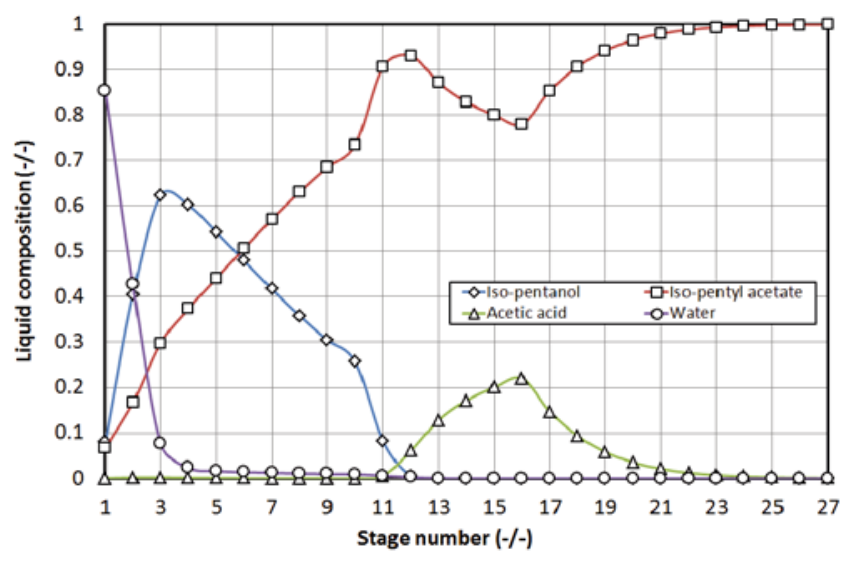

Figure 5. Stage-wise variation of compositions for reactive distillation (Case II)

maximum possible conversion that could be achieved in a reversible reaction; thus, the design of such a reactor can often be challenging. By contrast, the RD column needed no extra modification and could cost-effectively replace the conventional reactor and distillation system with higher product yield.

Figure 6 shows the temperature distribution of the $\mathrm{RD}$ column. The temperature decreased in the enriching section as the liquid moved down the column, and the water was stripped from the liquid phase. However, the temperature of the liquid remained almost constant in the stripping section, which mainly contained isoamyl acetate in the liquid phase.

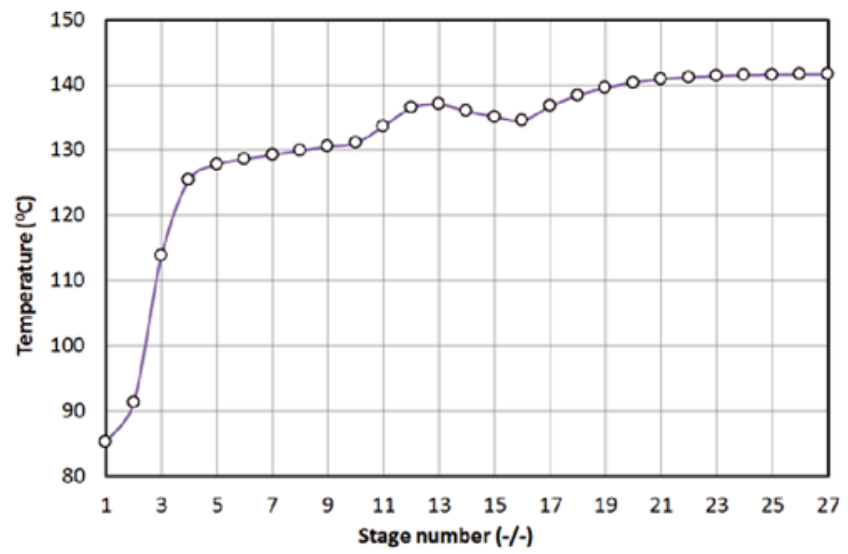

Figure 6. Temperature profile in the reactive distillation column (Case II)

To compare the economics of both processes, the required heat duties for the conventional distillation and $\mathrm{RD}$ processes were evaluated. The results are reported in Table 8. The condenser heat load was as much as sevenfold the conventional process compared with the corresponding RD process. Similarly, the reboiler duty was more than eight times higher for the conventional process. Besides a significant difference in the cost of utilities, a substantially larger condenser and reboiler are required for the conventional process. These requirements ultimately translate into higher capital and operating costs. A preliminary cost analysis was carried out and presented in Table 9. For conventional distillation,

Table 7. Conversion of isopentanol for conventional process and reactive distillation

\begin{tabular}{|l|c|c|}
\hline & Conventional distillation & Reactive distillation \\
\hline Conversion [\%] & $87.29 \%$ & $91.00 \%$ \\
\hline
\end{tabular}


Table 8. Heat duties for conventional and reactive distillation

\begin{tabular}{|l|c|c|}
\hline Heat Duty $[\mathrm{kW}]$ & Convention distillations & Reactive distillation \\
\hline Condenser & -9263.38 & -1316.03 \\
\hline Reboiler & 8529.35 & 1028.06 \\
\hline Reactor & 638.50 & - \\
\hline
\end{tabular}

Table 9. Cost comparison for reboiler and condenser for conventional distillation and reactive distillation

\begin{tabular}{|l|c|c|c|c|}
\hline \multirow{2}{*}{} & \multicolumn{2}{|c|}{ Convention distillation } & \multicolumn{2}{c|}{ Reactive distillation } \\
\cline { 2 - 5 } & Capital cost [USD] & Operating cost [USD/h] & Capital cost [USD] & Operating cost [USD/h] \\
\hline Reboiler & 146.300 & 22.75 & 79.600 & 3.29 \\
\hline Condenser & 365.700 & 266.57 & 130.000 & 39.28 \\
\hline
\end{tabular}

Basis: Cost of steam for reboiler $=17.95$ USD/ton; Cost of cooling water for condenser $=31.7$ USD/million liters.

the capital cost for the reboiler was almost $84 \%$ higher, whereas that for the condenser was even higher at $181 \%$. The operating costs for the reboiler and condenser were almost sevenfold higher for the conventional process compared with its RD counterpart. Our findings in the present case agreed with those reported by Estrada et $\mathrm{al}^{3}$ for naphtha hydrodesulfurization.

\section{Dynamic analysis}

Despite the inherent process efficiency and costeffectiveness with the application of RD in the previous section, its complex dynamics has to be appropriately considered for the successful initial design and subsequent scale-up, operation, and control of the process. In the present work, the dynamic response of the RD configuration was analyzed by introducing a step change in key process parameters. These input parameters included the heat duties of the reboiler and the condenser, as well as the feed of isopentanol. For each input parameter, the step change was analyzed for two cases. First, the input parameter was decreased by $10 \%$ of the steady state value at time $t=3 \mathrm{~h}$. In the second case, the input parameter was increased by $10 \%$ of the steady state at time $\mathrm{t}=3 \mathrm{~h}$.

Figure 7 shows the dynamic response of the RD column when the negative step change of $-10 \%$ was introduced in the heat duty of the reboiler at time $t=3 \mathrm{~h}$. The concentration of isoamyl acetate in the product decreased by $55.2 \%$, whereas its production decreased by $33.4 \%$. Notably, the step stage was introduced at $t=3 \mathrm{~h}$, but the remarkable decrease in composition could only be detected after $t=8 \mathrm{~h}$. Meanwhile, the mole flow of isoamyl acetate showed notable initial fluctuations after $t=6 \mathrm{~h}$ before ultimately settling to a lower steady-state

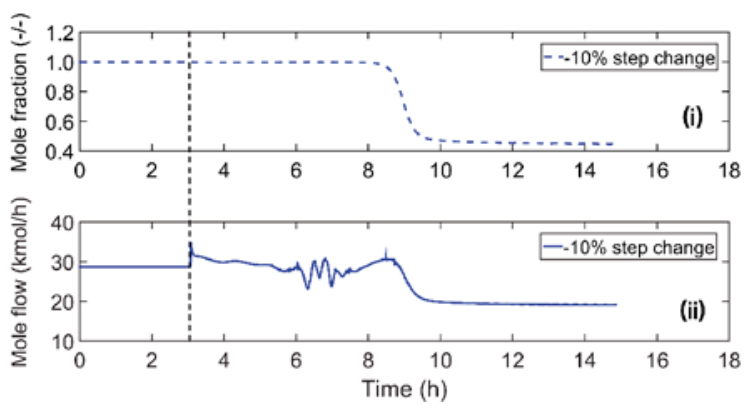

Figure 7. Dynamic response at negative $10 \%$ step change in the heat duty of the reboiler at time, $t=3 h^{\prime}$; (i) Composition of iso-amyl acetate at the bottom stream; (ii) Flow rate of iso-amyl acetate at the bottom stream value (Fig. 7(ii)), but the percent reduction was not as pronounced as that for the composition.

Figure 8 shows the effect of the negative step change on the time evolution of the temperature disturbance for different stages. Almost $3 \mathrm{~h}$ was required before the effect of the step change was clearly manifested on the column temperature profile. When the temperature decrease affected the beginning of the reaction zone in Stage 10 , water evaporation from the liquid phase decreased. In turn, the conversion level decreased because of the equilibrium constraint. Consequently, the liquid phase entering Stage 11 contained more water, which further lowered conversion at this stage and augmented the rate of temperature decrease. This phenomenon continued in all the stages of the reaction zone (i.e., Stages 10-15).

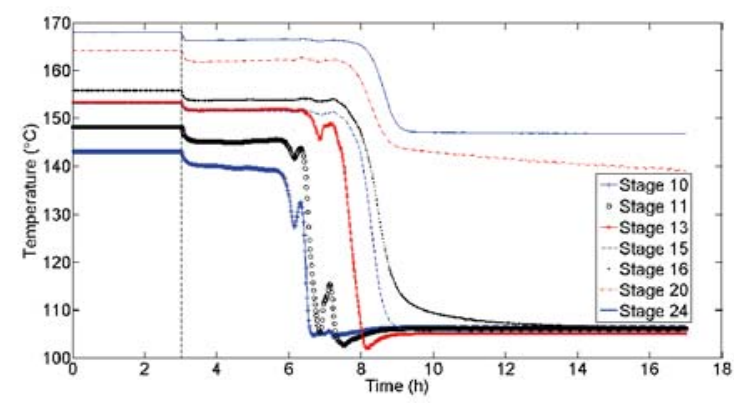

Figure 8. Effect of the step-change in the reboiler heat duty on the liquid temperature profiles for different stages

Therefore, conversion decreased as the liquid mixture with an increasingly higher fraction of water descended. A steep decrease in temperature occurred in conjunction with a steep increase in the water fraction (Fig. 9a). As the conversion decreased, less isoamyl acetate was produced and the unreacted components increased in the liquid phase. This trend was observed for various components of the liquid mixture at different stages, as highlighted by Figures 9b-9d.

Meanwhile, the effect of the positive step change in the composition was not as significant compared with the negative step change, as shown in Figure 10. However, isoamyl acetate flow was adversely affected. The product flow rate decreased by $35.1 \%$. Another notable difference between the two cases was that the time required to achieve a new steady state was comparatively short. The column required approximately $3 \mathrm{~h}$ to reach the steady state after the introduction of the step change.

Subsequently, we considered the effect of the disturbance in the condenser heat duty on the dynamic response of the RD column. Figures 11 and 12 show the time 
a)

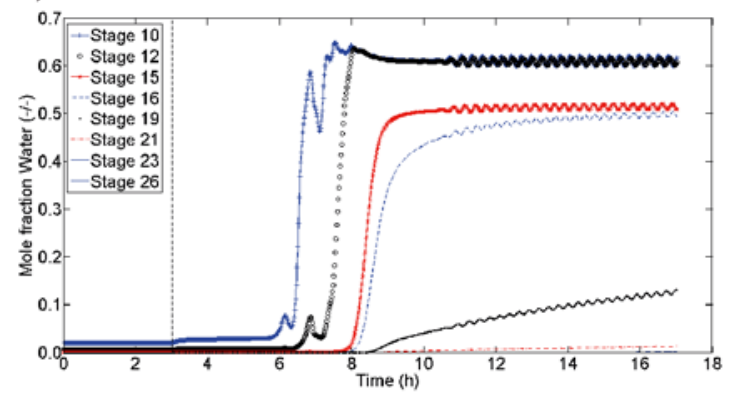

b)

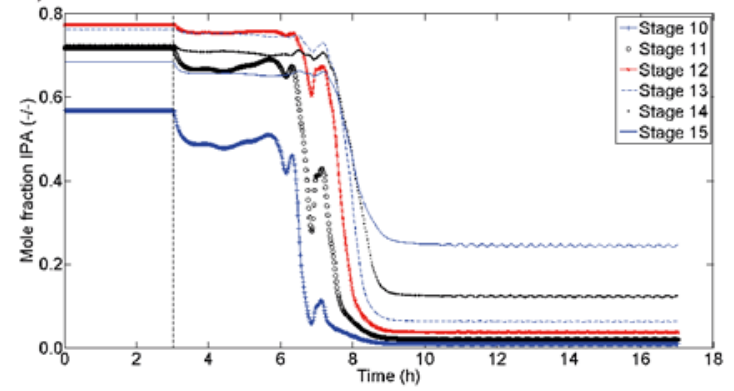

c)

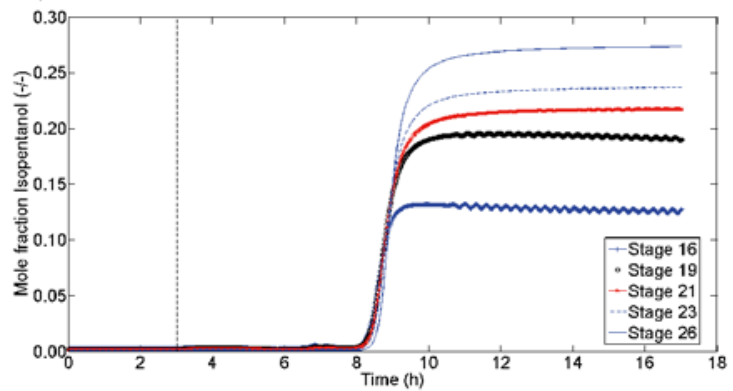

d)

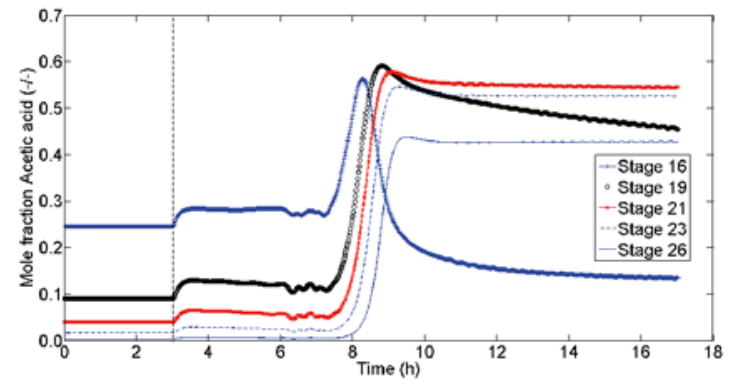

Figure 9. Change in composition of liquid in the trays due to the negative $10 \%$ step change in the heat duty of the reboiler at time, $t=3 h$; a) Water; b) Iso-amyl acetate; c) Iso-pentanol; d) Acetic acid

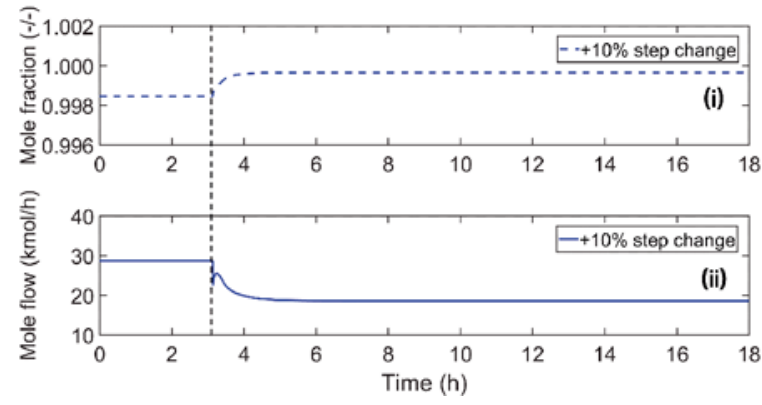

Figure 10. Dynamic response at positive $10 \%$ step change in the heat duty of the reboiler at time, $t=3 h^{\prime}$; (i) Composition of iso-amyl acetate at the bottom stream; (ii) Flow rate of iso-amyl acetate at the bottom stream

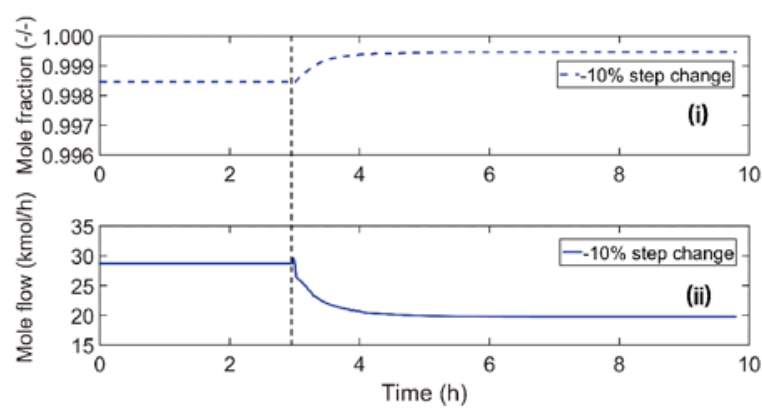

Figure 11. Dynamic response at positive $10 \%$ step change in the heat duty of the reboiler at time, $t=3 h^{\prime}$; (i) Composition of iso-amyl acetate at the bottom stream; (ii) Flow rate of iso-amyl acetate at the bottom stream

evolution of disturbance in the composition and the molar flow when a step change was introduced. The effect of the negative step change was not as pronounced as its positive counterpart as far as the composition and transients were concerned, despite a significant drop in its molar flow. A significant variation with the long transients was noted in the composition and flow when a positive step change was made. Notably, a positive step change in the condenser load showed similar behavior to

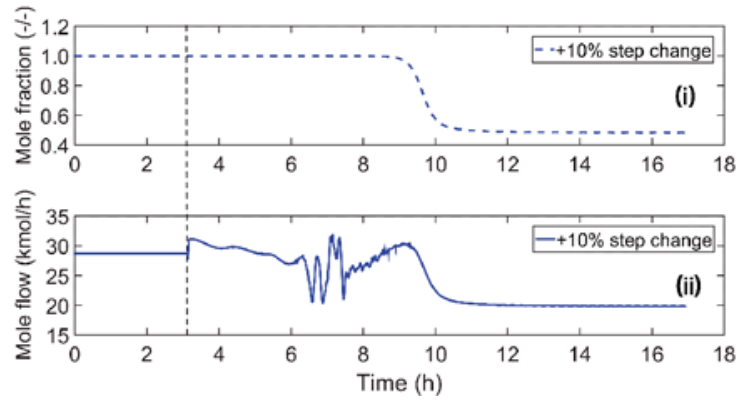

Figure 12. Dynamic response at positive $10 \%$ step change in the heat duty of the condenser at time, $t=3 h^{\prime}$; (i) Mole fraction of iso-amyl acetate at the bottom stream; (ii) Mole flow rate of iso-amyl acetate at the bottom stream

the negative step change in the reboiler heat duty. The lowering of the temperature was obviously the reason for both cases.

The effects of the step changes in the isopentanol feed rate are indicated in Figures 13 and 14. As expected, the decrease in the mole flow rate of isopentanol in the feed decreased the mole flow rate of isoamyl acetate in the product. However, the increased mole flow rate of isopentanol severely influenced the dynamics of RD such that the operation became unstable and the column could not reach a steady state even at $30 \mathrm{~h}$ after the introduction of the step change.

A summary of the effect of step changes is presented in Table 10. A $10 \%$ change in the heat duties of either condenser or reboiler significantly affected the product flow and produced comparable deviations. However, the composition was not always affected unless the introduction of step change decreased the temperature. In this case, an even higher reduction coupled with long transients in the composition of isoamyl acetate was observed. As far as the feed was concerned, a reduction in its flow rate did not alter the product composition, but its flow substantially decreased. By contrast, an increase in the feed led to unexpected dynamics. The operation 
Table 10. Change in molar flow rate and composition of iso-amyl acetate in the bottom stream due to the effect of disturbance in input parameters of the reactive distillation system

\begin{tabular}{|l|c|c|c|c|}
\hline \multirow{2}{*}{ Input parameter } & \multicolumn{2}{|c|}{ Iso-amyl acetate composition } & \multicolumn{2}{|c|}{ Iso-amyl acetate molar flow rate } \\
\cline { 2 - 5 } & $-10 \%$ change & $+10 \%$ change & $-10 \%$ change & $+10 \%$ change \\
\hline Reboiler heat duty & & & $-33.4 \%$ & $-35.1 \%$ \\
\hline Condenser heat load & $-55.2 \%$ & $-51.6 \%$ & $-31.1 \%$ & $-30.8 \%$ \\
\hline Iso-pentanol molar flow rate & $+0.062 \%$ & Unstable & $-16.6 \%$ & Unstable \\
\hline
\end{tabular}

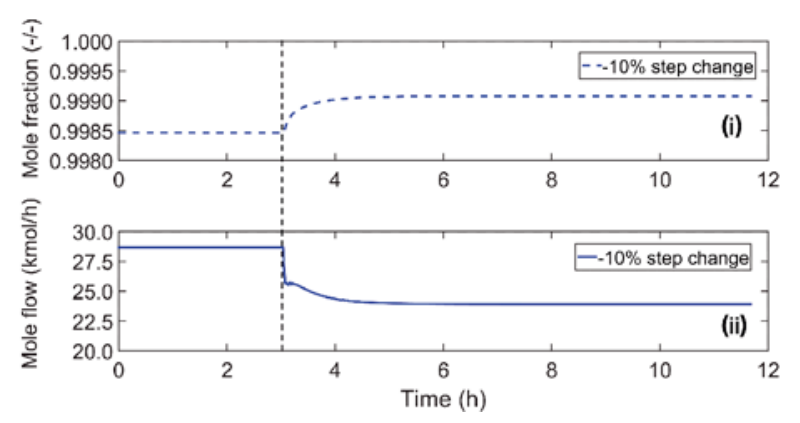

Figure 13. Dynamic response at negative $10 \%$ step change in the flow rate of iso-pentanol in the feed at time, $t=3 h^{\prime}$; (i) Mole fraction of iso-amyl acetate at the bottom stream; (ii) Flow rate of iso-amyl acetate in the bottom stream
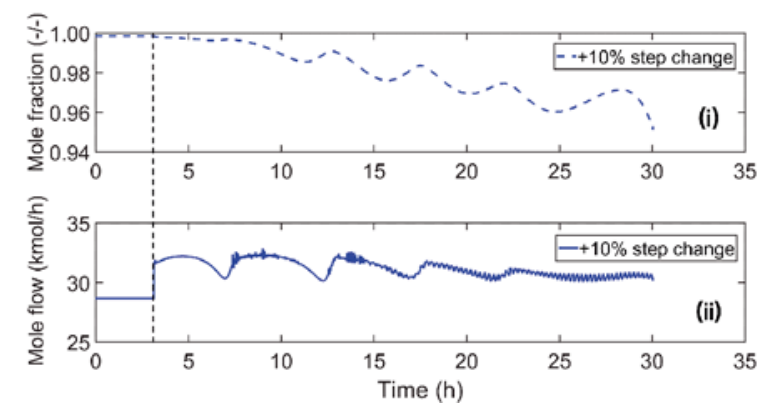

Figure 14. Dynamic response at positive $10 \%$ step change in the flow rate of iso-pentanol in the feed at time, $t=3 h^{\prime}$; (i) Mole fraction of iso-amyl acetate at the bottom stream; (ii) Flow rate of iso-amyl acetate in the bottom stream

of RD became unstable when the flow rate of the feed was increased by $10 \%$.

\section{CONCLUSION}

The present work employed a two-step strategy to evaluate the feasibility of isoamyl acetate production via $\mathrm{RD}$. In the first step, conditions for the conventional distillation and RD processes were optimized. To compare the cost-effectiveness of both processes, the heat duties of the condenser and reboiler, in addition to the conversion level, were evaluated under identical conditions. Several fold changes in the heat duties of the two processes translated into substantial differences in the process economics, such that the operating cost for the reboiler was seven times higher. For the condenser, the cost was almost eight times higher for the conventional process compared with RD. The required employment of larger heat exchangers for the condenser and reboiler was another factor that caused the cost escalation for the conventional process. The higher conversion of alcohol during RD is another feature of its cost-effectiveness.
The second step involved rigorous dynamic analysis of the same RD configuration subject to a $10 \%$ disturbance in the key process parameters. The negative and positive step changes in the feed flow and heat duties of the reboiler and condenser were considered. As far as condenser and reboiler heat duties were concerned, a $30 \%-35 \%$ decline in the product flow was observed. However, the product purity decreased by more than $50 \%$ when the heat duty lowered the temperature of either the condenser or reboiler. Meanwhile, a reduction in the alcohol feed hardly affected the product purity while the product flow declined by $17 \%$. When the disturbance resulted in more than a $50 \%$ decrease in the product purity, the process took as much as $8 \mathrm{~h}$ to stabilize after the occurrence of the disturbance. However, the positive fluctuation in the alcohol feed made the RD process unstable. The process did not stabilize even after $30 \mathrm{~h}$ of operation. Thus, the RD process is sensitive to external disturbances and requires an effective control scheme for efficient operation.

\section{ACKNOWLEDGEMENT}

The authors would like to extend their sincere appreciation to the Deanship of Scientific Research at the King Saudi University for its funding of this research work through the Prolific Research Group PRG-1437-31.

$\begin{array}{ll}\text { Nomenclature } \\ C_{\mathrm{CH}_{3} \mathrm{COOH}} & \text { Molar concentration of acetic acid, [mol/l] } \\ C_{\mathrm{C}_{5} \mathrm{H}_{11} \mathrm{OH}} & \text { Molar concentration of isopentanol, [mol/l] } \\ C_{\mathrm{C}_{5} \mathrm{H}_{11} \mathrm{COOCH} \mathrm{CH}_{3}} & \text { Molar concentration of iso-amyl acetate, } \\ C_{\mathrm{H}_{2} \mathrm{O}} & \text { [mol/l] } \\ G & \text { Molar concentration of water, [mol/l] } \\ k_{1} & \text { Gibbs energy, [kJ] } \\ & \text { Rate constant for forward reaction, } \\ k_{2} & {\left[\mathrm{kmol} / \mathrm{m}^{3} / \mathrm{s}\right]} \\ T & \text { Rate constant for backward reaction } \\ P & {\left[\mathrm{kmol} / \mathrm{m}^{3} / \mathrm{s}\right]} \\ P & \left.\text { Temperature of the system, [ }{ }^{\circ} \mathrm{C}\right] \\ x & \text { Pressure of the system, [atm] }\end{array}$

\section{Greek letters}

$\begin{array}{ll}\gamma_{i} & \text { Activity coefficient, }[-/-] \\ \tau_{i j} & \text { Dimensionless interaction parameters, }[-/-]\end{array}$

\section{LITERATURE CITED}

1. Tuchlenski, A., Beckmann, A., Reusch, D., Düssel, R., Weidlich, U. \& Janowsky, R. (2001). Reactive distillation - industrial applications, process design \& amp; scale-up. Chem. Engine. Sci. 56(2), 387-394. DOI: 10.1016/S00092509(00)00240-2. 
2. Luyben, W.L. \& Yu, C.C. (2008). Reactive distillation design and control (1st ed.). Hoboken, New Jersey, United States: John Wiley \& Sons.

3. Estrada-Villagrana, A.D., Quiroz-Sosa, G.B., JiménezAlarcón, M.L., Alemán-Vázquez, L.O. \& Cano-Domínguez, J.L. (2006). Comparison between a conventional process and reactive distillation for naphtha hydrodesulfurization. Chem. Engine. Proces.: Process Intensif. 45(12), 1036-1040. DOI: 10.1016/j.cep.2006.03.019.

4. Patil, K.D. \& Kulkarni, B.D. (2012). Mathematical modeling and simulation of reactive distillation column using matlab and aspen plus. Inter. J. Lat. Trends .Engine. Sci. Tech. 1(6), 1-8.

5. Sudibyo, Q., Murat, M.N. \& Aziz, N. (2012). Simulation studies and sensitivity analysis of methyl tert-butyl ether reactive distillation. $11^{\text {th }}$ International Symposium on Process Systems Engineering 31, 130-134. DOI: 10.1016/B978-0-44459507-2.50018-4.

6. Sharma, N. \& Singh, K. (2010). Control of reactive distillation column: A review. Inter. J. Chem. Reac. Engine. 8 R5. DOI: $10.2202 / 1542-6580.2260$.

7. Harmsen, G.J. (2007). Reactive distillation: The frontrunner of industrial process intensification: A full review of commercial applications, research, scale-up, design and operation. Chem. Engine. Proces.: Process Intensif. 46(9), 774-780. DOI: 10.1016/j.cep.2007.06.005.

8. Omota, F., Dimian, A.C. \& Bliek, A. (2003). Fatty acid esterification by reactive distillation. Part 1: Equilibrium-based design. Chem. Engine. Sci. 58(14), 3159-3174. DOI: 10.1016/ S0009-2509(03)00165-9.

9. Kiss, A.A. (2011). Heat-integrated reactive distillation process for synthesis of fatty esters. Fuel Proces. Technol. 92(7), 1288-1296. DOI: 10.1016/j.fuproc.2011.02.003.

10. Vargas, E.C., Hernandez, S., Hernandez, J.G.S. \& Rodriguez, M.I.C. (2011). Simulation study of the production of biodiesel using feedstock mixtures of fatty acids in complex reactive distillation columns. Energy 36(11), 6289-6297. DOI: 10.1016/j.energy.2011.10.005

11. Castro, F.I.G., Ramirez, V.R., Hernandez, J.G.S., Castro, S.H. \& El-Halwagi, M.M. (2013). Simulation study on biodiesel production by reactive distillation with methanol at high pressure and temperature: Impact on costs and pollutant emissions. Comp. \& Chem. Engine. 52, 204-215. DOI: 10.1016/j. compchemeng.2013.01.007.

12. Nguyen, N. \& Demirel, Y. (2011). Using thermally coupled reactive distillation columns in biodiesel production. Energy 36(8), 4838-4847. DOI: 10.1016/j.energy.2011.05.020.

13. Guo, B. \& Li, Y. (2012). Analysis and simulation of reactive distillation for gasoline alkylation desulfurization. Chem. Engine. Sci. 72, 115-125. DOI: 10.1016/j.ces.2012.01.016.

14. Hasabnis, A. \& Mahajani, S. (2014). Acetalization of glycerol with formaldehyde by reactive distillation. Indust. \& Engine. Chem. Res. 53(31), 12279-12287. DOI: 10.1021/ie501577q.

15. Bhatia, S., Mohamed, A.R., Ahmad, A.L. \& Chin, S.Y. (2007). Production of isopropyl palmitate in a catalytic distillation column: Comparison between experimental and simulation studies. Comp. \& Chem. Engine. 31(10), 1187-1198. DOI: 10.1016/j.compchemeng.2006.10.008.

16. Chandrakar, A., Agarwal, V., Chand, S. \& Wasewar, K.L. (2007). Modeling and simulation of catalytic distillation column for esterification of acetic acid with methanol. Inter. J. Chem. React. Engine. 5(1), 481. DOI: 10.2202/1542-6580.1404.

17. Sharma, M.M. \& Mahajani, S.M. (2003). Industrial applications of reactive distillation. In Reactive distillation: Status and future directions (1-29). Weinheim, FRG: Wiley-VCH Verlag GmbH \& Co. KGaA.

18. Saha, B., Teo, H. \& Alqahtani, A. (2005). Iso-amyl acetate synthesis by catalytic distillation. Inter. J. Chem. React. Engine. 3 A11. DOI: $10.2202 / 1542-6580.1250$.

19. Patil, K.D. \& Kulkarni, B.D. (2014). Kinetics studies on esterification reaction of acetic acid with iso-amyl alcohol over ion exchange resin as catalysts. Inter. J. .Engine. Res. 3(8), 488-493.

20. Saha, B., Alqahtani, A. \& Teo, H.T.R. (2005). Production of iso-amyl acetate: Heterogeneous kinetics and techno-feasibility evaluation for catalytic distillation. Inter. J. Chem. React. Engine. 3 A30. DOI: 10.2202/1542-6580.1231.

21. Luyben, W.L., Pszalgowski, K.M., Schaefer, M.R. \& Siddons, C. (2004). Design and control of conventional and reactive distillation processes for the production of butyl acetate. Indust. \& Engine. Chem. Res. 43(25), 8014-8025. DOI: 10.1021/ie040167r.

22. Lu, S., Lei, Z., Wu, J. \& Yang, B. (2011). Dynamic control analysis for manufacturing ethanol fuel via reactive distillation. Chem. Engine. Proces.: Process Intensif. 50(11-12), 1128-1136. DOI: 10.1016/j.cep.2011.09.006.

23. Olanrewaju, M.J. \& Al-Arfaj, M.A. (2005). Dynamic investigation of high-purity/high-conversion generic reactive distillation. Comp. Aid. Chem. Engine. 20, 811-816. DOI: 10.1016/S1570-7946(05)80257-3.

24. Santoso, H., Bao, J. \& Lee Peter, L. (2009). Operability analysis of mtbe reactive distillation column using a process simulator. Chem. Prod. Proc. Model. 4(3), 6. DOI: 10.2202/19342659.1376.

25. Khaledi, R. \& Young, B.R. (2005). Modeling and model predictive control of composition and conversion in an etbe reactive distillation column. Indust. \& Engine. Chem. Res. 44(9), 3134-3145. DOI: 10.1021/ie049274b.

26. Elliott, J.R. \& Lira, C.T. (2012). Introductory chemical engineering thermodynamics (2nd ed.). New Jersey, United States: Prentice Hall. 